\title{
Leader Interpersonal Emotion Regulation and Follower Performance
}

DOI:

10.1027/1866-5888/a000249

\section{Document Version}

Accepted author manuscript

Link to publication record in Manchester Research Explorer

\section{Citation for published version (APA):}

Vasquez, C., \& Niven, K. (2020). Leader Interpersonal Emotion Regulation and Follower Performance. Journal of Personnel Psychology, 19(2), 97. https://doi.org/10.1027/1866-5888/a000249

\section{Published in:}

Journal of Personnel Psychology

\section{Citing this paper}

Please note that where the full-text provided on Manchester Research Explorer is the Author Accepted Manuscript or Proof version this may differ from the final Published version. If citing, it is advised that you check and use the publisher's definitive version.

\section{General rights}

Copyright and moral rights for the publications made accessible in the Research Explorer are retained by the authors and/or other copyright owners and it is a condition of accessing publications that users recognise and abide by the legal requirements associated with these rights.

\section{Takedown policy}

If you believe that this document breaches copyright please refer to the University of Manchester's Takedown Procedures [http://man.ac.uk/04Y6Bo] or contact uml.scholarlycommunications@manchester.ac.uk providing relevant details, so we can investigate your claim.

\section{OPEN ACCESS}




\section{Journal of Personnel Psychology \\ Leader Interpersonal Emotion Regulation and Follower Performance \\ --Manuscript Draft--}

Manuscript Number:

Full Title:

Short Title:

Article Type:

Keywords:

Corresponding Author:

Corresponding Author Secondary

Information:

Corresponding Author's Institution:

Corresponding Author's Secondary Institution:

First Author:

First Author Secondary Information:

Order of Authors:

Order of Authors.

Order of Authors Secondary Information:

Author Comments:

Abstract:

\section{Opposed Reviewers:}

Funding Information:

Additional Information:

Question

Has this manuscript been submitted previously to this journal?

Has the manuscript or any component of it already been published or is currently under consideration by another journal?

JPPSY-D-19-00020R3

Leader Interpersonal Emotion Regulation and Follower Performance

LEADER EMOTION REGULATION AND FOLLOWER PERFORMANCE

Research Note

interpersonal emotion regulation; affect; task performance; leadership

Cristian Vasquez

The University of Manchester

Manchester, Lancashire UNITED KINGDOM

The University of Manchester

Cristian A. Vasquez

Cristian A. Vasquez

Karen Niven, PhD

Hector P. Madrid, PhD

Author Note

\section{Interpersonal emotion regulation (IER) refers to the actions of influencing other} people's feelings. Drawing on this construct and emotions-as-social-information theory, we argue that leader IER to improve or worsen followers' feelings would be related to followers affect and thereby to their performance. Results of a multisource survey study supported a mediation model in which leaders' attempts to improve their followers' feelings enhancing followers' task performance via the followers' experience of positive affect. In contrast, leaders' use of affect-worsening actions was associated with the experience of followers' negative affect, but not related to task performance. These findings contribute by expanding knowledge on the affective underpinnings of the leader-follower relationship and informing the development of leadership interventions aimed to foster employee performance.

CONICYT FONDECYT

(1115004)

Hector P. Madrid

\section{Response}

No

No 
Note: If a paper based, in whole or in part, on the present sample and/or data has already been published or is under consideration elsewhere, authors MUST reveal this and explain in their letter to the editor precisely how the paper contributes beyond previous submissions based on the same data.

Does the research meet ethical Yes

guidelines, including adherence to the legal requirements of the study country?

Do the authors have any conflicts of No interest?

State the word count of the manuscript 2488 including references but excluding tables and figures.

Has the manuscript been prepared Yes according to language and style recommendations of the Publication Manual of the American Psychological Association (6th ed.)?

Have you removed all references to author names and affiliations from the manuscript, tables, figures, and appendices to ensure an anonymous review process? 
Running head: LEADER EMOTION REGULATION AND FOLLOWER PERFORMANCE

Leader Interpersonal Emotion Regulation and Follower Performance

\author{
Cristian A. Vasquez \\ University of Manchester, UK \\ Karen Niven \\ University of Manchester, UK \\ Hector P. Madrid \\ Pontificia Universidad Católica de Chile
}

Author Note

Cristian A. Vasquez and Karen Niven, Alliance Manchester Business School, University of Manchester, UK. Hector P. Madrid, School of Management, Pontificia Universidad Católica de Chile.

The authors would like to thank Maximiliano Escaffi, Manchester Business School, Manchester University, UK, for helpful support on data management and analysis.

This research initiative was supported by CONICYT FONDECYT 11150004 award granted to Hector P. Madrid by National Commission of Scientific and Technological Research, Chile (CONICYT).

Correspondence concerning this article should be addressed to Cristian Vasquez, Alliance Manchester Business School, University of Manchester, Booth Street East, Manchester M13 9SS, United Kingdom. Email: cristian.vasquez@manchester.ac.uk 


\begin{abstract}
Interpersonal emotion regulation refers to the actions of influencing other people's feelings. We apply this construct to the context of leadership, to determine whether leader interpersonal emotion regulation may explain followers' performance. Drawing on emotions-associal-information theory, we argue that leader strategies to improve or worsen followers' feelings would be related to followers affect and thereby to their performance. We tested these proposals using a multisource field study involving 31 leaders and 157 followers. Results from multilevel modelling supported a mediation model in which leaders' attempts to improve their followers' feelings enhancing followers' task performance via the followers' experience of positive affect. In contrast, leaders' use of affect-worsening actions was associated with the experience of followers' negative affect, but not related to task performance. These findings contribute by expanding knowledge on the affective underpinnings of the leader-follower relationship and informing the development of leadership interventions aimed to foster employee performance.
\end{abstract}

Keywords:

interpersonal emotion regulation, affect, task performance, leadership 
Leader Interpersonal Emotion Regulation and Follower Performance

Interpersonal emotion regulation (IER) refers to the deliberate and controlled actions by which a person initiates, maintains or changes the occurrence, intensity or timespan of others' affect, and involves the use of strategies to improve or worsen followers' feelings (Niven, Totterdell, \& Holman, 2009). This behavior has been viewed as relevant to the dynamics of the workplace, with studies suggesting that IER is a process that has effects on relationship quality and individuals' well-being (Troth, Lawrence, \& Jordan, 2017).

Here, we apply the notion of IER to the leadership context, with the aim of examining whether leaders can alter their followers' emotions in order to elicit desired performance effects. While there have been some attempts to study leaders' use of IER, these have mostly been within the context of laboratory settings and those studies in the field have only captured attempts to improve followers' feelings (Little, Gooty, \& Williams, 2016). Thus, the effects of both affectimproving and affect-worsening IER on followers' feelings and core aspects of their task performance are still scantly examined in the organizational psychology research. Drawing on the theory of emotion-as-social-information (Van Kleef, 2009), we examined whether leader affect-improving and -worsening IER would lead to positive and negative followers' affect, and if this in turn leads to follower performance. Thus, we contribute to the literature on leadership and IER by expanding the knowledge on leaders' influential behaviors, and explicitly demonstrating the role that IER can have in followers' affect and their performance.

\section{Theoretical Development}

According to Niven, Totterdell and Holman (2009), the process of regulating others' emotions is expressed in two sets of behaviors. Affect-improwing IER involves provoking 
positive feelings in interaction partners (e.g., enthusiasm, inspiration), whereas affect-worsening IER elicits negative affect in others (e.g., worry, nervousness).

Adopting emotion-as-social-information (EASI; Van Kleef, 2009) framework, the relationship between IER and affect can be explained due to the expression of affect communicate to others the agent's goals, attitudes, and intentions, which are captured by the targets' cognitive inferences. Based on this, supportive evidence indicates that leaders' displays of emotion can influence followers' behavior and performance (Koning \& Van Kleef, 2015). Thus, we propose that IER may involve similar processes, such that, when a leader uses affectimproving IER (e.g. demonstrating interest in followers' problems) followers could infer that the leader is concerned about their well-being, which ought to elicit positive affective reactions. Conversely, when a leader uses affect-worsening IER behaviors, such as criticizing, followers are likely to infer a lack of care about the relationship, resulting in negative affective reactions. Additional support for our proposals can be found in the observed effects of leadership relative to the affective experience of followers. Favorable leader behaviors, such as those involved in supportive and transformational leadership, are related to followers' positive experiences, for example, engagement (Tims, Bakker, \& Xanthopoulou, 2011). In contrast, unfavorable leadership behavior, for instance abusive leadership, leads to followers' negative states such as frustration, strain or exhaustion (Skakon, Nielsen, Borg, \& Guzman, 2010). Based the above, we derived the following hypotheses:

Hypothesis 1: Leader affect-improving IER will be positively related to follower positive affect.

Hypothesis 2: Leader affect-worsening IER will be positively related to follower negative affect. 
Our second proposal is that leader IER influences followers' performance through its association with follower affect. Theory on motivational underpinnings of affect bring insights into this claim, by describing two general motivational systems underlying the relationship between affect and behavior, namely, Behavioral Approach System (BAS) and Behavioral Inhibition System (BIS) (Carver, Avivi, \& Laurenceau, 2008). BAS is associated with positive affect, such that when individuals feels positive feelings, they increase their effort and dedication to reward-seeking behaviors. Thus, followers' positive emotional experiences give them more energy and lead them to expect more positive outcomes, which may lead them to perform better in their tasks. In contrast, BIS involves the experience of negative affect, which is associated to the presence of threats in the environment and has been linked to the tendency to avoid and withdraw from the contextual situation. Thus, individuals may reduce their performance, because they are likely disengaged from the tasks given the adverse affective state experienced. Importantly, some studies have reported positive effects of negative emotions on performance, depending on boundary conditions, such as individual's sense of control and social support (George \& Zhou, 2007). However, the continuous interactions involving the experience of negative affect and the imbalance of power between leaders and their followers may lead to impaired cognition and behavior of followers, especially when is the leader the source of followers' negative affect (Skakon, Nielsen, Borg, \& Guzman, 2010). Thus, drawing on the above, we propose two mediational processes, stating that follower affect is the medium by which leader IER is related to follower performance:

Hypothesis 3: Follower positive affect will mediate the positive relationship between leader affect-improving IER and task performance. 
Hypothesis 4: Follower negative affect will mediate the negative relationship between leader affect-worsening IER and task performance.

\section{Method}

\section{Procedure}

We conducted a multisource survey study with a retail organization in Chile. Employees responded to a survey providing ratings of their leader's IER and their own affect. In an independent survey, leaders provided ratings of each of their followers' performance. 157 employees nested in 31 leaders took part of the study. On average, supervisors were associated with $5.06(\mathrm{SD}=1.41)$ followers. Participants were $72 \%$ male, average age was 31.2 years $(\mathrm{SD}=$ $8.62)$, and mean job tenure was 3.6 years $(\mathrm{SD}=5.27)$. Job roles were $48.4 \%$ selling agents, $10.8 \%$ administrative, $5.1 \%$ technical, $8.3 \%$ professional staff, $4.6 \%$ manager and $12.7 \%$ others.

\section{Measures}

Leader IER was measured using 13-items adapted from Niven et al. (2011). Followers indicated the extent to which their leader uses strategies to improve the way they feel, e.g., “discusses team members' positive characteristics" $(\alpha=.95)$ or worsen the way they feel, e.g., “talks about team members' shortcomings" $(\alpha=.91)$, on a 5-point scale (not at all - a great extent). Followers' affect was measured with a 6-items scale of Warr, Bindl, Parker, \& Inceoglu (2014), which asked followers to rate the extent to which they experience an array of feelings on a response scale of 1: never - 5: always/almost always. Items were "enthusiastic", "joyful” and "inspired" for positive affect $(\alpha=.81)$, and "worried", "anxious" and "tense" for negative affect $(\alpha=.68)$. Followers also reported interaction frequency with their leaders with the single item "how frequently do you interact with your leader?" (1: almost never - 5: everyday), for use as a control in subsequent analyses. Finally, we use Oldham \& Cummings (1996) three-item scale to 
measure individual task performance in terms of effort, quality, and quantity (1: little/low - 7: much/high; $\alpha=.86)$.

\section{Results}

Confirmatory factor analysis showed acceptable goodness-of-fit for a five-factor model defined by leader improving and worsening IER, follower positive and negative affect, and follower task performance, $\chi^{2}=343.59, d f(199)$, RMSEA $=.07$, CFI $=.94^{1}$. Means, standard deviations, correlations and reliabilities are summarized in Table 1.

We tested our hypotheses using multilevel structural equation modelling with MPlus, because employees were nested in their respective leaders. In support of Hypotheses 1 and 2, results showed a positive association between leaders' affect-improving IER and follower positive affect, $b=.33, S E=.06, p<.01$, and a positive association between leaders' affectworsening IER and follower negative affect, $b=.34, S E=.07, p<.01$. Also, results of mediation analysis showed a positive indirect effect between leaders' affect-improving IER, follower positive affect and task performance, Monte Carlo CI 95\% [.06, .19], supporting Hypotheses 3. Finally, mediation analyses revealed a non-significant direct effect between the mediator and

\footnotetext{
${ }^{1}$ Goodness-of-fit of this five-factor solution was significantly better than two alternatives threefactor solutions. The first model loaded measures of task performance in one factor, improving and worsening IER in another factor, and positive and negative affect in another single factor, $\Delta \chi^{2}(7)=418.83, p<.01$. The second model loaded measures of task performance in one factor, affect-improving IER and positive affect in another factor, and affect-worsening IER and negative affect in another single factor, $\Delta \chi^{2}(7)=214.24, p<.01$.
} 
task performance, $b=-.13, p>.05$, such that a mediation process was not likely. As a result, hypothesis 4 was not supported. ${ }^{2}$

\section{[INSERT TABLES 1 AND 2 AND FIGURE 1 AROUND HERE]}

\section{Discussion}

Our findings indicate that leader IER has a proximal effect on followers' affect and a more distal influence on followers' task performance. Leader affect-improving IER was positively related to followers' positive affect, which in turn was positively related to their task performance. Conversely, leader affect-worsening IER was positively related to followers' unpleasant feelings. However, we did not find a significant relationship between followers' negative affect and their task performance. Drawing on EASI, the relationship between leader IER and followers' affect is likely due to the latter's inferences about the intentions of leaders about their well-being and motivation, such that affect-improving would involve authentic interest, whereas the opposite applies to affect-worsening. Regarding the associations of followers' affect with their performance, they are explained by the motivational meaning embedded in the affective experience. As such, positive affect entails approach motivation, which increases the likelihood of making things happen. However, the case of negative affect seems to involve more complexity. Although negative feelings involve avoidance tendencies, they might also adopt an approach meaning depending on the context (Carver, Avivi, \&

\footnotetext{
${ }^{2}$ Supplementary analysis revealed that leader affect-worsening IER exerts a significant negative indirect effect on follower performance via follower positive affect, Monte Carlo CI 95\% [-.23, .07]. This result will be discussed in the discussion section. Thanks to the anonymous reviewer who suggested this analysis.
} 
Laurenceau, 2008). The requirement for social interaction might play a role here, such as negative feelings could lead to better performance when interdependence among employees is needed, but no relationship between these variables is likely when the request for interdependence is absent (Madrid, Totterdell, Niven, \& Vasquez, 2018). Thus, further research examining possible boundary conditions for the effect of negative affect on follower performance is still needed. Alternatively, as suggested by the supplementary analysis conducted, it may be the case that leaders' affect-worsening IER exerts an effect on follower performance reducing the experience of positive affect, which suggests greater complexity in the model outlined.

Our research contributes to apply this form of affective behavior to the work context, by developing a theoretical rationale based on the integration of IER with emotions-as-socialinformation theory. Also, we contribute to the literature by providing evidence that leaders influence follower performance via the pathway of follower affect. In practical terms, our findings have implications for developing leadership interventions aimed to foster employee performance. Because leaders' IER has the potential to influence followers' affect and behavior, practitioners should consider training programs addressing IER. For example, leaders could be informed about the benefits of generating positive affect in their followers and specific ways in which they can do so.

Despite its strengths, such as the use of multisource data and multilevel analysis based on dozens of leader-follower dyads, the current research also has some limitations. Causal directions of the relationships we proposed can only be theoretically inferred, such that leaders' performance appraisals might predict followers' ratings of affect and leader IER. This might be explained due to biases in the perceptions of followers, because more positive assessment of 
their task performance by leaders might conduct to an increased experience of either positive or negative affect and positive or negative perceptions of leaders' behavior. Furthermore, commonmethod variance could threaten the effects estimated in the relationship between leader IER and follower affect. Moreover, the lack of effect on the relationship between negative feelings and performance might be due to the limited reliability of the negative affect measure. These measurement issues might imply that individuals are assessing specific negative emotions in a different way, which may affect the estimation of the relationship between negative affect and performance. Also, we only adopted in theoretical fashion the proposals of EASI and approach/avoidance motivation, but they were not tested in the study. Finally, the study was conducted in a single organization, which may limit the external validity of the results observed. Thus, further research should address the above issues to determine if the findings of this study are robust and generalizable.

To sum up, in this research note we aimed to understand the effects of interpersonal emotion regulation in leader-follower relationships, showing that this affective behavior could be relevant for employee affect and task performance. We trust that future research and practice will follow and expand on the knowledge developed here. 


\section{References}

Carver, C. S., Avivi, Y. E., \& Laurenceau, J. (2008). Approach, avoidance, and emotional experiences. In A. J. Elliot (Ed.), Handbook of approach and avoidace motivation. New York, NY: Psychology Press.

George, J. M., \& Zhou, J. (2007). Dual tuning in a supportive context: Joint contributions of positive mood, negative mood, and supervisory behaviors to employee creativity. Academy of Management Journal, 50, 605-622. http://dx.doi.org/10.5465/amj.2007.25525934

Koning, L. F., \& Van Kleef, G. A. (2015). How leaders' emotional displays shape followers' organizational citizenship behavior. Leadership Quarterly, 26(4), 489-501. http://doi.org/10.1016/j.leaqua.2015.03.001

Little, L. M., Gooty, J., \& Williams, M. (2016). The role of leader emotion management in leader-member exchange and follower outcomes. Leadership Quarterly, 27(1), 85-97. http://doi.org/10.1016/j.leaqua.2015.08.007

Madrid, H. P., Totterdell, P., Niven, K., \& Vasquez, C. A. (2018). Investigating a process model for leader affective presence, interpersonal emotion regulation, and interpersonal behaviour in teams. European Journal of Work and Organizational Psychology, 27(5), 642-656. http://doi.org/10.1080/1359432X.2018.1505719

Niven, K., Totterdell, P., \& Holman, D. (2009). A classification of controlled interpersonal affect regulation strategies. Emotion, 9(4), 498. http://doi.org/10.1037/a0015962

Niven, K., Totterdell, P., Stride, C. B., \& Holman, D. (2011). Emotion Regulation of Others and Self (EROS): The Development and Validation of a New Individual Difference Measure. Current Psychology, 30(1), 53-73. http://doi.org/10.1007/s12144-011-9099-9

Oldham, G. R., \& Cummings, A. (1996). Employee creativity: Personal and contextual factors at 
work. Academy of Management Journal, 39(3), 607-634. http://dx.doi.org/10.5465/256657

Skakon, J., Nielsen, K., Borg, V., \& Guzman, J. (2010). Are leaders' well-being, behaviours and style associated with the affective well-being of their employees? A systematic review of three decades of research. Work \& Stress, 24(2), 107-139. https://doi.org/10.1080/02678373.2010.495262

Tims, M., Bakker, A. B., \& Xanthopoulou, D. (2011). Do transformational leaders enhance their followers' daily work engagement? The Leadership Quarterly, 22(1), 121-131. https://doi.org/10.1016/j.leaqua.2010.12.011

Troth, A., Lawrence, S., \& Jordan, P. (2017). Interpersonal Emotion Regulation in the Workplace: A Conceptual and Operational Review and Future Research Agenda. International Journal of Management Reviews, 20(2), 523-543. https://doi.org/10.1111/ijmr.12144

Van Kleef, G. A. (2009). How emotions regulate social life: The emotions as social information (EASI) model. Current Directions in Psychological Science, 18(3), 184-188. http://dx.doi.org/10.1111/j.1467-8721.2009.01633.x

Warr, P., Bindl, U. K., Parker, S. K., \& Inceoglu, I. (2014). Four-quadrant investigation of jobrelated affects and behaviours. European Journal of Work and Organizational Psychology, 23(3), 342-363. http://doi.org/10.1080/1359432X.2012.744449 


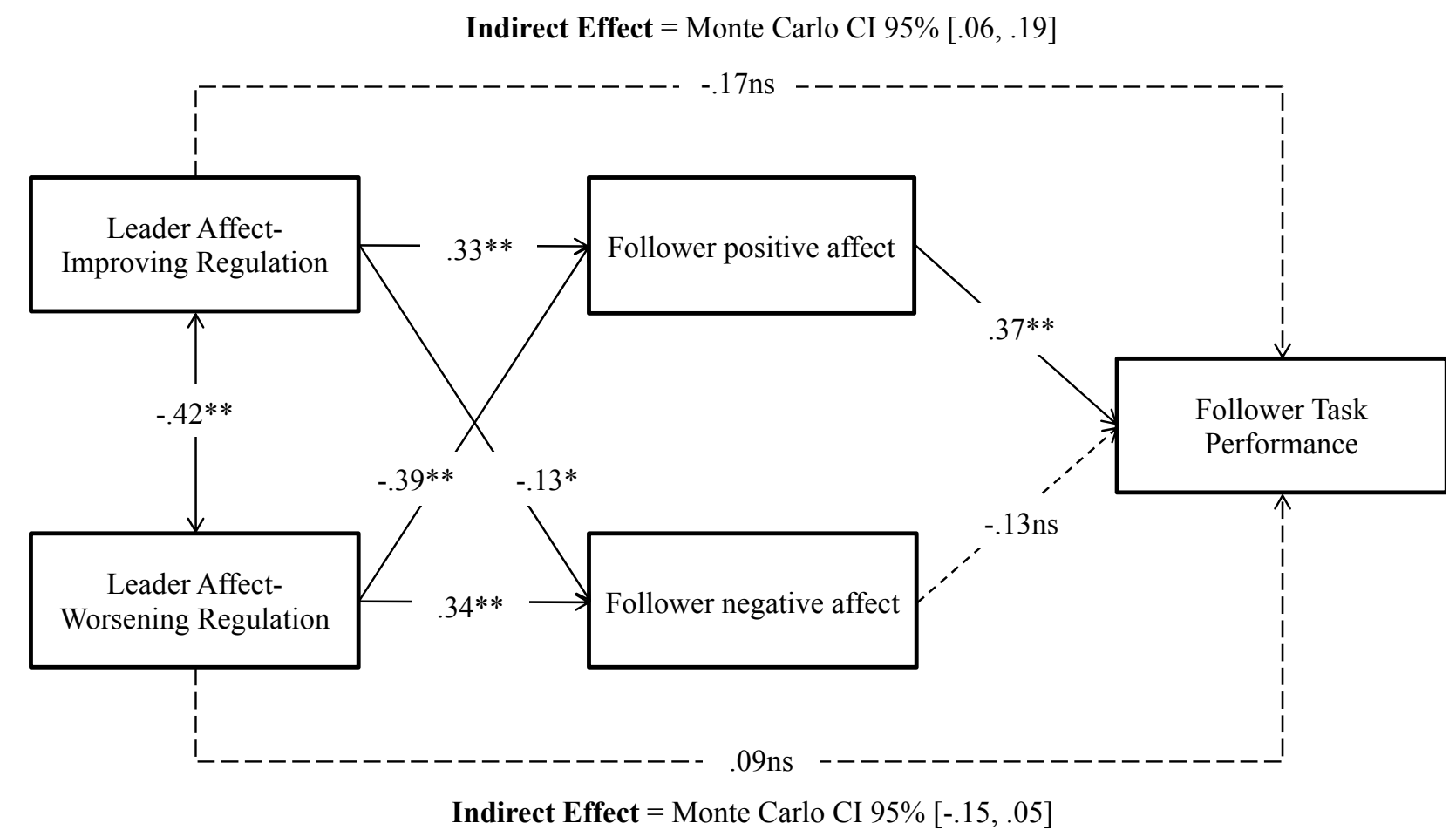

Figure 1. Path Analyses for Leader Interpersonal Emotion Regulation, Follower Affect and Follower Task Performance 
Table 1. Means, Standard Deviations, Correlations, and Reliabilities

\begin{tabular}{|c|c|c|c|c|c|c|c|c|}
\hline Variable & $\mathbf{M}$ & SD & 1 & 2 & 3 & 4 & 5 & 6 \\
\hline 1. Leader-follower interaction frequency & 4.05 & 1.13 & - & & & & & \\
\hline 2. Follower task performance & 5.19 & 1.24 & $.23 * *$ & $(.87)$ & & & & \\
\hline 3. Follower positive affect & 3.66 & 0.88 & $.33 * *$ & $.20 *$ & $(.81)$ & & & \\
\hline 4. Follower negative affect & 3.14 & 0.81 & $-.25 * *$ & -0.09 & $-.40 * *$ & $(.68)$ & & \\
\hline 5. Leader affect-improving regulation & 3.35 & 1.15 & $.46^{* *}$ & 0.05 & $.53 * *$ & $-.31 * *$ & $(.95)$ & \\
\hline 6. Leader affect-worsening regulation & 1.95 & 1.11 & $-.34 * *$ & 0.05 & $-.56 * *$ & $.36^{* *}$ & $-.63 * *$ & (.91) \\
\hline
\end{tabular}

Note. $N=157$. Reliabilities are displayed in parentheses on the diagonal. $* p<.05 . * * p<.01$. 
Table 2. Multilevel Analysis for Leader IER, Follower Affect, and Follower Task Performance

\begin{tabular}{|c|c|c|c|}
\hline Variable & Positive Affect & Negative Affect & $\begin{array}{c}\text { Task } \\
\text { Performance }\end{array}$ \\
\hline Intercept & $3.40(.62)^{* *}$ & $3.24(.23)^{* *}$ & $0.67(15.73)$ \\
\hline Leader-follower interaction frequency & & & $.28(.07)^{* *}$ \\
\hline Leader affect-improving regulation & $.33(.06)^{* *}$ & $-.13(.06)^{* *}$ & $-.17(.11)$ \\
\hline Leader affect-worsening regulation & $-.39(.04) * *$ & $.34(.07)^{* *}$ & $.09(.15)$ \\
\hline Follower positive affect & & & $.37(.09)^{* *}$ \\
\hline Follower negative affect & & & $-.13(.15)$ \\
\hline$R^{2}$ Model & $.42 * *$ & $.22 *$ & $.15^{*}$ \\
\hline Indirect effect $($ Monte Carlo $=20000)$ & {$[.06, .19]^{*}$} & {$[-.15, .05]$} & \\
\hline [CI 95\%] & & & \\
\hline
\end{tabular}

Note. $N=45$. Unstandardized estimates. $* p<.05$. $* * p<.01$ 